\title{
Chapter 8 \\ From an Unknown Other to an Attachment Figure: How Do Mental Representations Change as Attachments Form?
}

\author{
Vivian Zayas, Gül Günaydin and Yuichi Shoda
}

In adulthood, long-term pair bonds confer a number of beneficial psychological and physical benefits. Irrespective of the level of relationship satisfaction, partners are capable of regulating each other's physiological systems, daily mood, and affective states, as well as eating and sleeping patterns (Selcuk et al. 2010). Most important, partners in long-term pair-bonds are capable of alleviating physiological and psychological distress and promoting feelings of security in each other-such emotion regulation benefits is one of the defining features of attachment bonds.

A key and well-supported assumption in the literature is that these observable manifestations of adult pair bonds reflect the functioning of mental representations, or internal working models. Mental representations are the residue of past experiences with the particular partner, as well as experiences from other past and present relationships experienced directly or indirectly, stored in memory. Mental representations are powerful because they implicitly affect perceptions and expectations about likely events (e.g., if I seek help, then I will be supported), which in turn guide behaviors. Their influence extends beyond the relationship with the partner to interactions with friends, colleagues, acquaintances, and unknown others, and even to behaviors in seemingly asocial settings (e.g., when at work or alone), and may do so even without one's awareness (Günaydin et al. 2012).

Interestingly, although the field of adult attachment has uncovered much about the structure, content, functioning, and ontology of the mental representations underlying attachment relationships, little is known about the processes by which mental representations form, develop, and are maintained in adult pair-bonds. That is, how do mental representations change as a relationship develops from one between two strangers to one between two acquaintances and casual friends to a dating

\footnotetext{
V. Zayas $(\bowtie)$

Department of Psychology, Cornell University, 238 Uris Hall, Ithaca, NY, 14853-7601, USA e-mail: vz29@cornell.edu

G. Günaydin

Department of Psychology, Bilkent University, Ankara, Turkey

Y. Shoda

Department of Psychology, University of Washington, Seattle, USA

(C) Springer Science+Business Media, LLC 2015

V. Zayas, C. Hazan (eds.), Bases of Adult Attachment,

DOI 10.1007/978-1-4614-9622-9 8
} 
relationship characterized by romantic and sexual interest to a full-fledged attachment bond capable of regulating various psychological and physiological systems?

In the present chapter, we explore the metamorphosis that two individuals undergo as they form a pair bond. We describe a social cognitive framework for beginning to understand the changes that unfold at the level of mental representations as individuals go from two strangers whose lives and "minds" are relatively asynchronous and independent to two individuals in a full-fledged attachment relationship whose lives and minds are intertwined and synchronized. We propose that the positive psychological and physical outcomes, as well as the emotion regulatory effects, observed in pair bonds occur as a result of the two individuals developing elaborated mental representations of one another and extensive associations between the representation of the self and that of the partner. Moreover, as a result of having extensive experiences with the other person, frequently encountered interactions (If I'm upset, then my partner will comfort me) eventually become automatic and no longer require the actual person for the psychological and physical benefits to be realized. In a sense, through the elaboration of partner (and self) mental representations, the two people begin to form a linked or "coupled" cognitive system.

To describe our social cognitive approach to normative development of mental representations of adult attachment relationships, the present chapter is organized into four sections: First, we provide a brief review of what is known about the processes by which adult romantic attachments form. Second, we describe a social cognitive framework, personality-in-context (PiC) approach (Zayas et al. 2002), for conceptualizing developmental processes of change necessary for adult attachment formation. Our model draws from research on relationship turning points (e.g., first kiss, exclusivity; Baxter and Erbert 1999; Bolton 1961), which are events associated with changes (i.e., subsequent increases or decreases in commitment) in relationship trajectories, and how they may provide fertile ground for the evolution of the mental representations underlying the relationship. Third, we review and integrate existing empirical work, from diverse fields, on what is known about mental representations at various stages of attachment formation into this framework. We end by raising unanswered questions and discussing fruitful avenues for future empirical work on adult attachment formation and development processes.

\section{Attachment Formation in Adult Attachment Relationships}

Perhaps the best starting point to thinking about the development of adult attachment bonds is theorizing on the development of infant-caregiver bonds (Bowlby 1982; Hazan et al. 2004; Hazan and Zeifman 1994; Zeifman and Hazan 1997). In infant/caregiver relationships, attachment bonds are believed to form through four stages. In the preattachment phase (0-2 months), the infant is open to accepting care from anyone. In the attachment-in-the-making phase (2-6 months), the infant begins to discriminate among caregivers by differentially directing various social signals and selectively responding to certain caregivers. In the clear-cut attachment 
phase (after 6-7 months), the infant displays all four behaviors that define a fullfledged attachment bond. These are proximity-seeking, safe haven, separation distress, and secure base. And finally, in the goal-corrected partnership phase (after 36 months), as a consequence of cognitive maturation and the construction of a mental representation of the caregiver, the infant experiences less stress from temporary separations and a relative decline in proximity-seeking behaviors because she or he understands that the caregiver will eventually return.

Drawing from the infant attachment literature, Hazan and colleagues (Hazan et al. 2004; Zeifman and Hazan 1997) have proposed an analogous four-stage developmental framework to the formation of attachment bonds between two adults. In the preattachment phase, individuals get to know and seek proximity to potential romantic partners by what is colloquially referred to as "flirting," but critically in this stage, attachment behaviors are not directed exclusively to specific individuals. In the attachment-in-the-making phase, individuals preferentially seek proximity to a specific romantic partner and engage in various behaviors promoting attachment formation (e.g., self-disclosures, physical contact, mutual gazing, kissing, sex). In the clear-cut attachment phase, all behaviors that define an attachment bond are organized around the romantic partner. Now, the partner helps alleviate stress even when he or she is not physically present, and separations from the partner cause distress as well as disrupting regulation of affect and physiology. In the goal-corrected partnership phase, the representation of the partner becomes further elaborated and has a greater influence on person perception and stress alleviation.

\section{Theoretical Framework}

\section{Personality-in-Context (PiC) Approach}

The stages of attachment development identified by Hazan and colleagues provide an organizing framework for delineating how attachment bonds form and develop over time. Less is known, however, about how this development occurs at the level of mental representations of attachment figures. To address this central question, we draw on the PiC approach (Mischel and Shoda 1995; Shoda and Mischel 1998; Zayas et al. 2002). PiC is a social-cognitive metatheory that provides a framework for understanding how two individuals go from being strangers - a stage in which their lives and minds are independent and asynchronous - to a full-fledged pair bond - a stage in which the lives and minds of both individuals are intricately intertwined. In this section, we aim to describe basic concepts of the PiC approach (for a detailed description see Zayas et al. 2002) and extend them towards developing a normative model of adult attachment relationships.

Each Person's CAPs Network. To illustrate key principles, Fig. 8.1 provides a schematic of highly simplified CAPS networks of two individuals, referred to as Sam and Terry. The PiC approach conceptualizes each person's "mind" as a 

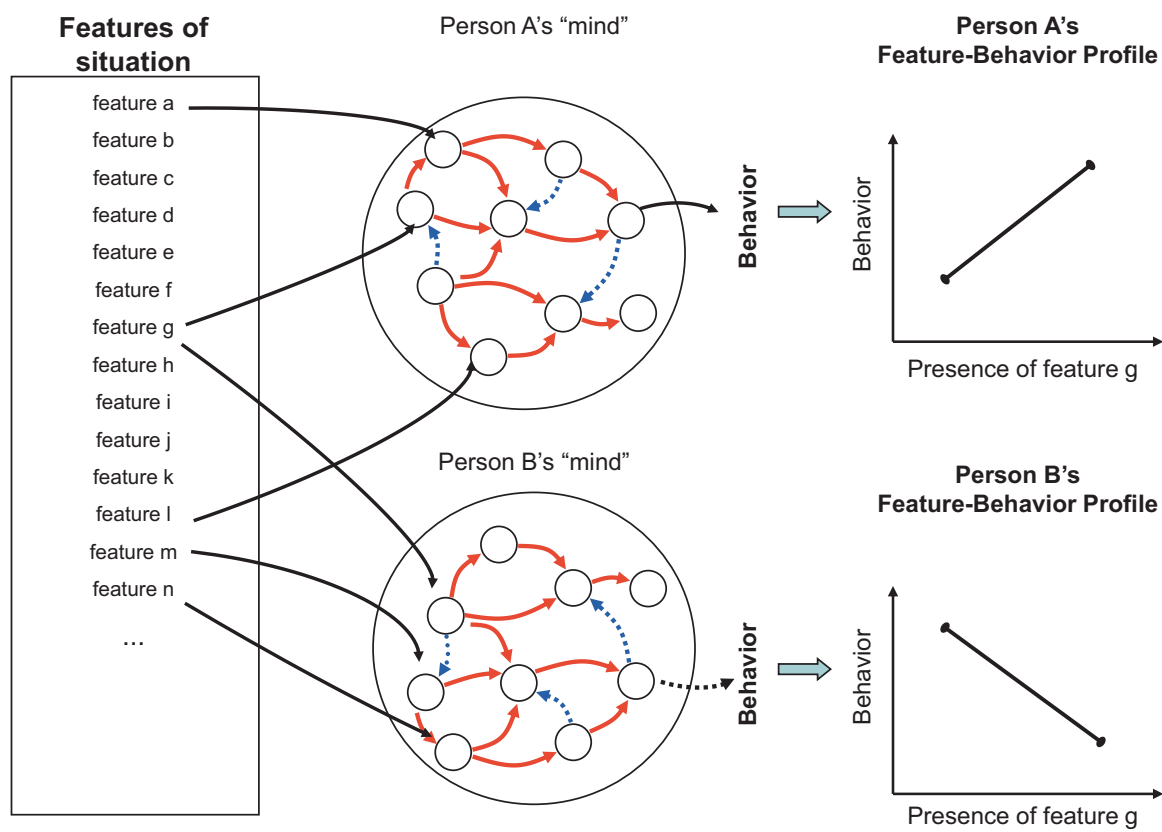

Fig. 8.1. Schematic representation of the cognitive-affective processing system (CAPS) for two hypothetical individuals (i.e., Person A, Sam, and Person B, Terry). Each person's mind is conceptualized by a stable network of interconnected cognitions and affects that mediates the effect of the situational features on behavior. Solid lines within and outside of the network represent excitatory associations (e.g., activation of one cognition automatically activates associated cognitions). Dotted lines within and outside of the network represent inhibitory associations (e.g., activation of one cognition makes it more difficult to activate associated cognitions). In the above illustration, each person encounters the same situation that consists of a common set of features (e.g., $a$ through $n)$. Because not all the features are meaningful for all people, Person $A$ and Person $B$ differ in the specific situational features that activate (or inhibit) certain cognitions and affects within each person's network, which in turn lean to a behavioral response. Figure reproduced from Zayas et al. (2008)

distinctive and stable system of interconnected cognitions and affects (also referred to as cognitive-affective processing system or CAPS network). These cognitions and affects, which are sometimes referred to as cognitive-affective units or CAUs, are essentially another term for mental representations. Thus, for the purpose of this chapter, change in mental representations is synonymous with change in a person's CAPs network, and vice versa. CAUs represent affective reactions (basic evaluations of goodness or badness to full-blown feelings and emotions), encodings (schemas and categories of self, others, events, and objects), expectations and beliefs (about the world and likely outcomes in particular situations), abstract goals (desired and undesired outcomes, goals and life projects), and competencies and self-regulatory plans (behavioral scripts that organize action).

Such social cognitive associationist approaches are not new to attachment theory. For decades, they have been fruitfully applied to understanding the complexity of 
the mechanisms of attachment working models (see Bartz et al., this volume). These frameworks draw on social cognitive ideas, such as availability and temporary and chronic accessibility (e.g., Bruner 1957; Higgins and King 1981), to understand interindividual or attachment style differences - why different people experience attachment relationships so differently - as well as intraindividual variability in experiences - why a given individual may feel secure in one relationship or at one moment in time, but not in another relationship or at a different moment in time. A key assumption of social cognitive approaches is that, each person's unique network of cognitions and affects mediates how he or she perceives, reacts, and behaves to particular situations. It is assumed that, the presence of a situational cue either external (in the environment) or internal (generated by one's own thoughts) activates a subset of cognitions and affects within the person's network. For example, if Sam has an upsetting encounter with a work colleague, this situation might activate a subset of encoding units within Sam's CAPS network (e.g., fear of disapproval, being excluded), which then via principles of spreading activation activates other associated cognitions and affects (e.g., feelings of insecurity and incompetence), which, in turn, gives rise to Sam's behaviors (e.g., defensiveness and anger). However, if Sam is instead enjoying the company of friends, this situation might activate a different subset of encoding units within Sam's network, which will in turn lead to a different subjective experience and behaviors.

Accounting for attachment style (interindividual) differences. Each person's network is distinct, as illustrated by comparing Terry's and Sam's network in Fig. 8.1. The networks differ in (i) the availability of the particular cognitions and affects within each person's network, as well as (ii) the accessibility of available cognitions and affects determined by the pattern and strengths of their interconnections. Individual differences are assumed to arise as a result of differences in the pattern of interconnections among available cognitions and affects.

To illustrate, imagine that Sam has had a couple of significant romantic relationships, both of which have been characterized by supportiveness and responsiveness, whereas Terry has had a string of difficult relationships in which there was little trust with previous partners. For both individuals, the residue of these past experiences becomes crystalized in memory and leads to changes in their networks. For Sam, the mental representation of past romantic partners is likely to be strongly connected to other CAUs encoding experiences of supportiveness, whereas for Terry the mental representation of past romantic partners is likely connected to other CAUs encoding untrustworthiness. Differences in both the patterning and strength of associations among CAUs characterizing the two people's networks contribute to the ease with which certain thoughts and feelings and behavioral repertoires become activated in particular situations. For Sam, attributions that a current partner is behaving in a supportive manner are likely to become spontaneously activated even in ambiguous situations, whereas such attributions might require much more effort for Terry who has less positive experiences. These differences in networks are expected to account for differences in the chronic accessibility of certain cognitions and affects (e.g., characteristic ways of encoding a situation), which in turn produce predictable differences between people in their behavioral responses and patterns. 
Accounting for intraindividual variability across situations and across relationships. The functioning of the network is able to account for variability within a given person's ongoing behavior, such as, why Sam might be anxious when having a confrontation with a colleague, but relaxed when spending an evening with friends. At least in the short term, the internal organization of each person's cognitive-affective processing system itself remains relatively stable and invariant, even though the particular thoughts and affects activated at a given moment change, depending on the situational input that activates them.

If ... then ... situation ... behavior patterns: Behavioral Signatures. To the extent that a person encounters situations with similar features, the same CAPS subnetwork will become activated in those situations, generating similar behavioral responses. Although the underlying network is difficult to assess directly, the observable manifestations of the network dynamics are distinctive and stable if ... then ... situation ...behavior...relationships between features of situations (i.e., ifs), on one hand, and behavioral responses (i.e., thens), on the other. These if...then... situation-behavior relationships are assumed to uniquely describe the consistency within a person's behavioral variability across situations. For example, if Sam has a conflict with a colleague, then she feels anxious. And, this if...then... profile is expected to be stable and characterize Sam's behaviors over time.

This point is particularly relevant to the present chapter on how an attachment bond develops. If the observable if...then... situation-behavior relationships of a person change, then presumably the underlying network has changed also. Thus, changes in behavioral signatures with regards to behavioral dynamics of two individuals may provide behavioral markers that their networks (i.e., partner and self representations) are also changing.

Conceptualizing the situation, or "ifs," as one's partner

Past social cognitive approaches to the attachment dynamics have conceptualized the situation or ifs in terms of the presence (or absence) of an interpersonal threat that activates (or deactivates) the attachment behavioral system (Mikulincer et al 2002), or as a particular relationship partner that affects the specific working models active in a given moment (Baldwin et al. 1996). Building on this tradition, the $\mathrm{PiC}$ approach assumes that the most significant aspects of the situation, that is, the "ifs," - both metaphorically and literally speaking - are one's partner and her behaviors.

The PiC approach assumes that in close relationships, particularly those that involve romantic partners, the thoughts, feelings, and behaviors of one partner come to matter more, and a large and integral part of one partner's environment is the behavior of the other partner. For example, fast forward and imagine that Sam and Terry are now in a full-fledged pair bond. As shown in Fig. 8.2, once a dyad is formed, the behavior of one partner, Sam $\left(B_{1}\right)$, emerges from the interaction between her "mind" or network $\left(P_{1}\right)$ and the situational input provided primarily by her partner's behavior, Terry $\left(B_{2}\right)$, hence $B_{1}=f\left(P_{1}, B_{2}\right)$. Similarly, the behavior of the other partner in the dyad, Terry $\left(B_{2}\right)$, can be conceptualized as a function of the interaction between his "mind" or network $\left(P_{2}\right)$ and the situational information provided by his partner's behavior, $\operatorname{Sam}\left(B_{1}\right)$, hence $B_{2}=f\left(P_{2}, B_{1}\right)$. 


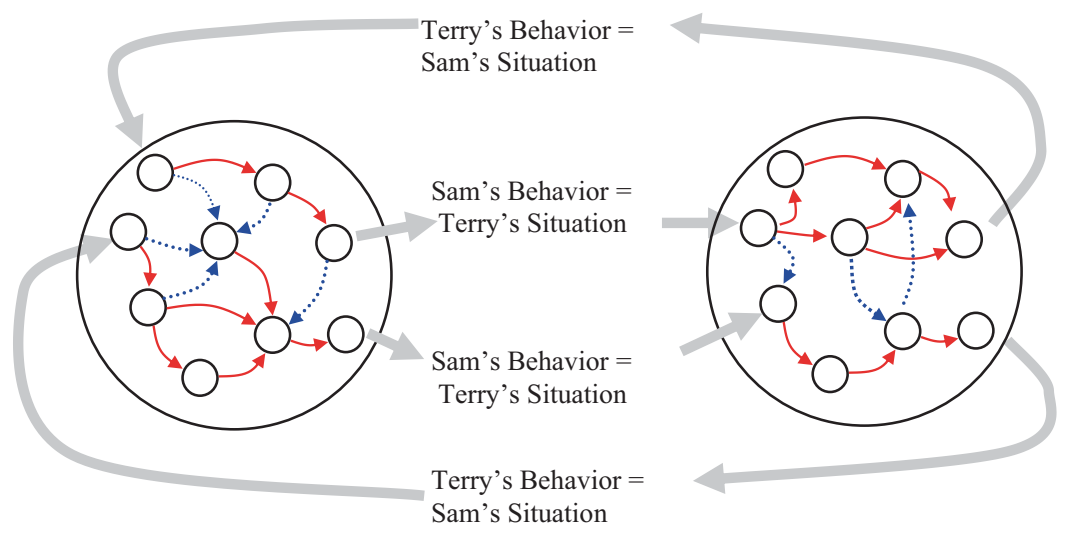

Fig. 8.2. The "interlocking" of the CAPS networks of two members of a dyad. As individuals develop a relationship, the CAPS networks of each partner become "interlocked" so that the significant part of the situations encountered by one partner consists of the behaviors of the partner, and vice versa. In the hypothetical scenario, Sam and Terry have begun to form a relationship. The resulting dyadic system which consists of Sam's and Terry's CAPS networks begins to become interconnected in such a way that the behavioral output from Sam's CAPS network becomes Terry's situation. This situation, in turn, is the input that activates a particular cognitive-affective dynamic in Terry, leading to Terry's behavior. Similarly, the behavioral output from Terry's CAPS network becomes Sam's situation, which in turn, activates in Sam a particular cognitive-affective dynamic, leading to her behavior. In this manner, a dyadic interpersonal system starts to develop, and once formed may account for consistency and stability within interpersonal relationships. Figure adapted from Zayas et al. (2002)

\section{Interlocking of Two CAPS Networks: The Dyadic System}

How does such a dyadic system, as represented in Fig. 8.2, develop? Two assumptions are central for understanding how dyadic systems emerge. First is the idea that situations with similar features tend to activate the same CAPS subnetworks, which in turn are expected to generate similar behavioral responses and second is the assumption that in close relationships the behavior of one partner is the situational input for the other. In combination, these two assumptions suggest that if one partner's behavior is relatively consistent over time (e.g., one's partner is sensitive and responsive especially when the other is distressed), then, in effect, the other partner is repeatedly exposed to situations that involve similar features (a responsive and sensitive partner), which in turn will repeatedly activate a specific subset of cognitions and affects in her CAPS network (e.g., comfort and alleviation of distress). Over time of repeatedly encountering these situations, the particular cognitive-affective dynamics that become activated in one partner in response to the other partner's specific behaviors may become increasingly more accessible and in future interactions might start to become activated with minimal behavioral input.

Returning to Sam and Terry, in the early phase of the relationship, if Sam experiences distress as a result of the confrontation with a colleague, she may need 
to obtain concrete physical and verbal comfort from Terry to experience relief. However, if over time, Sam repeatedly experiences relief from distress as a result of the behavior of Terry, then an association between the mental representation of her partner (Terry) and relief becomes encoded in memory. Eventually, simply the thought of her partner is sufficient to experience distress-relieving benefits. In social cognitive terms, the cognitive-affective dynamics characterizing distress-relief have become chronically accessible.

Furthermore, as a relationship develops, each partner is learning (implicitly or explicitly) about how her partner behaves in different situations and in a sense, begins to develop a mental representation of the partner. For example, early on in the relationship, Sam may have to explicitly communicate to Terry that she is upset and why. At this point, Terry may not yet be able to read her subtle cues of distress (e.g., Sam tends to be less talkative when upset). However, as the relationship develops and with repeated interactions, Sam may no longer have to explicitly express when she is upset. Now, Terry may be much attuned to any subtle changes in her verbal and nonverbal cues that signal distress and can provide comfort even without any explicit communication. He may even become particularly adept at knowing exactly what she needs depending on the source and nature of the distress.

Once the mental representation of each partner is formed, an individual may be more likely to engage in top-down, schema-driven processing (rather than bottomup, stimulus-driven processing) and consequently, may interpret the behaviors of her partner as consistent with the schema. Over time, we expect that two individuals will form a dynamic dyadic system that generates stable and predictable patterns of behavior (see Fig. 8.2). The resulting dyadic system is dynamic in the sense that the specific cognitions and affects that become activated within the CAPS network of each person of the dyad, as well as the observable behaviors that each CAPS network produces, are not constant, but vary from moment-to-moment depending on the situational input (i.e., partner's behaviors).

\section{A Model of Adult Attachment Formation}

The PiC approach begins to provide a conceptual framework for understanding how a dyadic relationship forms. However, many questions remain about the processes contributing to the formation of a dyadic system in general and the formation of an attachment bond specifically. To develop a process model of adult attachment formation, we not only draw on $\mathrm{PiC}$, but also bring together two distinct lines of work. We draw upon the relationship literature on turning points (Bolton 1961). These are relationship events that are important because they are associated with subsequent increases and decreases in the dyad's commitment level. We also draw upon the learning and memory literature that speaks to how novel information becomes stored in long-term memory.

1. Turning Points The manner in which two individuals solve the challenges posed by particular turning points has implications for the linking of the two systems. 
Work on relationship development has shown that couples go through key turning points in their relationships (e.g., first kiss, exclusivity, etc.) that are associated with increases (and in some cases decreases) in relationship commitment (Baxter and Bullis 1986). Each type of turning point, such as spending time together, is associated with particular cues (e.g., partner scent, mannerisms, personal history) and interactions (e.g., comfort, sexual arousal) that may elicit certain psychological, behavioral, and physical changes in the person him or herself.

Moreover, turning points are associated with psychological themes. At each turning point, couples experience increased tension between competing interpersonal motives and goals (e.g., independence versus connectedness; Baxter and Erbert 1999). How two individuals resolve these conflicts undoubtedly has implications for the linking of the two systems, via overlapping partner and self representations, and thus profoundly affects the formation of the attachment bond, as well as its quality (promoting security or insecurity). For example, siding towards greater connectedness should go hand in hand with greater interconnectedness of the partner and self mental representations in each person's mind. Conversely, if conflicts engendered by turning points lead to siding towards greater independence, then the partner and self mental representations will remain separate and distinct within the mind of both individuals.

Thus, the set of cues associated with a particular turning point is large, including all the sensory information about the partner and changes to the self, as well as implicit learning about the partner's behaviors and the self, and any meta-cognitions (e.g., thoughts and feelings about the meaning of particular events) that arise from the resolution of conflicting motives. We propose that the turning points (either a singular event or events reoccurring over a period of time) are times during which significant learning about the relationship partner, the self, and the self-in-relationto-partner occurs. This learning is reflected in enduring changes in the mental representations of the individuals in the dyad (i.e., changes in each person's CAPs networks) and the resulting representation leads to changes at the level of affect, thought, and behavior within the relationship.

2. Learning process from co-occurrence in short-term memory to permanent changes in representations in long-term memory. We suggest that these turning points are fertile ground for each partner undergoing significant changes in their mental representations - i.e., changes in each person's CAPs network. In turn, these changes in the minds of the individuals naturally give rise to changes in the subsequent functioning of the two individuals.

The idea that learning, particularly associative learning, is involved in the formation of attachment bonds is not new. The role of associative conditioning in attachment has long been discussed in both the human (see also Acevedo, Bartz et al., and Beckes and Coan, this volume) and animal literature (Cairns 1966; Hofer 1994). Extrapolating from these literatures, it is assumed that through the course of a relationship, partners become conditioned to various features of one another, and that these cues regulate distinct physiological, affective, cognitive, and behavioral systems. 
Here we extend theory and research on learning processes to the development of adult attachment relationships. Specifically, we extend past work by proposing that what is learned is contingent on the various external cues (e.g., partner's scent, verbal and nonverbal behaviors) and internal cues (e.g., one's own internal motivations and states) during key turning points in the relationship. Drawing from the memory literature (Atkinson and Shiffrin 1968; Hebb 1969; Tulving 1972), we suggest that the mental representation of the partner, the self-in-relation-to-partner, and the relationship itself builds over time in two-phases. First, the set of cues present during turning points simply co-occur with the activation of the existing mental representation of the partner in short-term memory, which has a fairly limited capacity. We hypothesize that the coactivation of the partner representation with the various cues elicited by the turning point first occurs in short term memory. The more one is exposed to the cues, or the more that one uses cue-relevant information, the greater likelihood that the information will become stored in long-term memory. Because the turning point, by definition, provides novel cues (or novel constellation of cues) not previously encountered, the set of cues are highly salient, which further contributes to their encoding and storage in memory.

Second, information about the partner is gradually transferred from short-term memory into long-term memory. With repeated exposure to cues present during turning points, or single exposure if the cues are highly potent, the cues increasingly become associated with mental representations and are expected to leave a permanent trace in long-term memory, thus resulting in stable and enduring changes in mental representations. Moreover, unlike short-term memory with limited capacity and rapid decay, long-term memory can store unlimited amounts of information indefinitely. Thus, the resultant mental representation of the partner is expected to exert its influence on behaviors within and outside of the relationship.

Through this learning process, we expect that the mental representations that characterize each individual at different points in the relationship undergo significant change in their structure. They are elaborated and increasingly linked with the self-representation, and thus lead to mental representations that characterize a different stage in the relationship.

\section{What Are the Key Turning Points at Each Stage of Adult Attachment Forma-} tion? Is it possible to identify a finite set of turning points that predictably shape the course of adult attachment formation? This is a daunting task. The literature suggests that relational development is quite diverse (Huston et al. 1981). Moreover, although most people report experiencing turning points in their relationships, members of the same dyad rarely report the same key events and may experience the same event in drastically different ways (Sillars and Scot 1983; see also Christensen and Nies 1980; Jacobson and Moore 1981). Such variability in the events that play a significant role in relationship development is even greater across relationships. For example, of 80 participants (40 couples), only 10 participants listed the "first kiss" as a turning point in the relationship, and only 23 participants listed "first sex" as a turning point (Baxter and Bullis 1986). 
Nonetheless, based on the extant research on turning points and work on adult attachment, there are a few natural candidates. Work by Baxter and colleagues has identified 26 turning points, which were further subdivided into 14 supratypes. Although turning points with respect to commitment levels is not the same as turning points with respect to an attachment bond, this list provides a reasonable empirically based starting point from which to identify events in relationship development that might foster, or hinder, the formation of an attachment bond. Among the turning points identified, not surprisingly, there were a few key attachment-related turning points, such as, get to know time (first meeting), quality time, physical separation, reunion, provision of support, and serious commitment, which we consider in this chapter.

\section{The PiC Approach in Action: Revisiting the Story of Sam and Terry}

To illustrate the basic ideas of the PiC approach to adult attachment formation, let's return to the story of Sam and Terry. They first met at a party hosted by a mutual friend. They remained acquaintances for a few months, seeing each other at social gatherings. At this point, the mental representation that each person had of the other was based primarily on their previous experiences with others, such as partners, parents, and friends, as well as broader social categories about what one knows about different types of people. All these experiences are encoded in memory and are all used in the service of making sense of newly encountered others.

However, based on the attraction and relationship literature, a few key ingredients are likely to put the two on a path to forming an attachment bond. One is attraction, whether dispositionally the two are drawn to each other based on each other's physical and psychological characteristics or situationally given the particular events in their life situation. In the story of Sam and Terry, each finds the other attractive. Sam is immediately smitten by Terry's dry wit, and Terry is captivated by Sam's appearance. They also share a few common interests, which fans the initial spark. However, perhaps equally as important, situational factors push them together as well. They both have recovered from their most recent relationship and are in a time in their lives in which they are interested in dating with the possibility of more. Everyone in their social circle thinks they are perfect for one another. And, each of their families is ready for them to settle down.

With forces of attraction drawing the two together, over time, Sam and Terry increasingly spend more time together. They try out the latest restaurants, spend the evening listening to live music, and walk through the farmer's market on weekends. Not surprisingly, their initial attraction and time together increases the likelihood of experiencing more emotionally and physically intimate events (first kiss, first sexual encounter, deciding to be exclusive), which provide opportunities for Sam and Terry to learn about each other and to develop a representation of themselves in relation to one another. Turning points provide novel cues or constellation of cues, 
that when presented repeatedly over time build up the mental representation of the partner. The mental representation of the partner is expected to become increasingly complex in terms of shear amount of information, its interconnection with existing representations, and particularly its interconnections with representations of the self.

These turning points also provide opportunities for each person to meet the needs of the other. The safe haven provision is one of the defining features of adult attachment relationships. The first time that Terry is distressed and comforted by Sam sets the stage for learning, explicitly and implicitly, that Sam can be counted on for support in the future, and perhaps more importantly, that her behaviors or even mere presence and sound of her voice are soothing. For a full-fledged attachment bond to form, these types of interactions in which the safe haven provision is met, must be encountered repeatedly.

Over time, these experiences are expected to become crystalized in the minds of both individuals. From a PiC approach, this process of changing mental representations is conceptualized as enduring changes in the networks (pattern and strength of existing associations) of the two individuals. These changes are reflected in greater associations between the partner mental representation and the self representation, as well as how these are associated with various cognitive, affective, and behavioral responses. The new pattern of associations affects encoding of the partner's behavior, and the cognitive and affective reactions that the encoding activates. Thus, as a result of learning that occurs in the early stages of a relationship as individuals encounter key events, the networks of the two individuals become increasingly attuned to each other, which in turn contributes to synchronization of the two individuals' affective, cognitive, physiological, and behavioral responses.

In addition, because the behavioral manifestations of each person's network are the stable if (situation)...then (behavior) ... patterns, as the networks of the two individuals change so too should we expect to see changes in their if...then... patterns. For example, in the early stage of their relationship, if Sam happened to arrive at a party upset from the day's events, Terry's presence might only provide minimal relief and would be incapable of regulating affective and physiological systems. However, in a full-fledged pair bond, even a simple reminder of Terry (e.g., thinking of him, seeing his photograph, receiving a text message) is capable of inducing feelings of calm. Similarly, whereas separations from Terry early on would not disrupt basic physiological and psychological functioning, critically, these systems would be severely affected by separation in a full-fledged pair bond.

\section{Reviewing and Integrating Existing Literature Within this Framework}

How does one go from being unattached to attached? More specifically, what are the changes that occur at the level of the mental representation as an attachment bond develops? To date, there is little empirical longitudinal evidence documenting 
these changes. Instead, there is research on mental representations at various stages of relationship development, starting from a rich body of social cognition research on mental representations of unknown others and acquaintances, which is the state that most individuals start out at, to the extensive work in the area of adult and child attachment on the deep influences of attachment representations. Here we summarize literature from diverse fields, including social and cognitive psychology and neuropsychology, for clues to the possible changes in representations as individuals form an attachment bond in adulthood. We also highlight how particular turning points in the relationship may promote changes in the mental representation at each stage and possible areas for future inquiry. Although we are not proposing that these turning points can only occur in specific stages, based on the literature, we identify the stages in which they are likely to occur in order to illustrate the $\mathrm{PiC}$ approach to adult attachment formation.

We divide this section into three parts reflecting the stages of attachment development that have been identified in previous work (e.g., Zeifman and Hazan 1997). Preattachment, attachment-in-the-making, and clear-cut attachment/goal-corrected partnership. Towards the end, we illustrate how the $\mathrm{PiC}$ approach can be used to inform adult attachment formation by continuing with our hypothetical scenario of Sam and Terry.

\section{Preattachment}

A defining feature of the preattachment stage is that attachment behaviors are not exclusively directed to the future partner. Indeed, in this initial stage, when two individuals first meet, they have very little information about one another. However, even so, research suggests that instead of possessing no mental representation of one another, or possessing some sort of "blank slate" on which experiences with the person are etched, individuals come into these situations making a number of inferences about one another (e.g., Andersen and Baum 1994; Goodwin et al. 2002), even based on minimal nonverbal and verbal cues (e.g., for a review see Macrae and Quadflieg 2010). These initial impressions and inferences (e.g., whether the other person is attractive, funny, or competent) are important because they strongly affect the extent to which the two individuals are drawn towards each other and likely to encounter various key events or turning points that further pull them towards (or away from) one another. In a sense, inferences, albeit not necessarily conscious, can serve to either highlight some individuals as potential partners, or eliminate them from contention.

1. Initial Impressions: When the Past Affects the Present. The objective characteristics of each person (e.g., physical attractiveness) are important factors in these initial impressions, and people possessing certain characteristics (e.g., symmetrical faces) are consensually viewed as more attractive and desirable. Indeed, viewing attractive faces activates dopaminergic regions of the brain implicated in reward processing such as ventral striatum and nucleus accumbens (e.g., Aharon et al. 2001; Kampe 
et al. 2001). Nonetheless, there is considerable variability across people in who and what features and qualities they find attractive. Even seemingly objective cues are evaluated in an idiosyncratic manner and these individual differences have been also shown to activate regions in the brain involved in reward-processing, such as the orbitofrontal cortex (Kim et al. 2007).

The subjective nature of first impressions, and the evidence that "beauty is in the eye of the beholder" (Hönekopp 2006) is not surprising given the assumption that a person's unique network, which reflects a history of life experiences and genetic, temperamental, and biological predispositions, affects how they construe and evaluate any given situation, including potential partners. From an attachment perspective, mental representations of significant others, which is a key CAU in people's networks, are highly chronically accessible and are expected to color, in a spontaneous fashion, evaluations and inferences of novel others, including evaluations of potential mates. Research by Andersen and colleagues, for example, has shown that when a new person shares attributes with a significant other, the existing mental representation is spontaneously activated and used to make sense of the new person-a phenomenon referred to as transference (e.g., Andersen and Chen 2002; Andersen and Baum 1994). In recent work, novel others who bore minimal facial resemblance to women's current romantic partner were evaluated more positively (e.g., intelligent, trustworthy, attractive), even though the participants were not aware of the physical resemblance (Günaydin et al. 2012). Other studies have similarly found that physical resemblance to significant others (e.g., Kraus and Chen 2010; White and Shapiro 1987) have a profound influence on first impressions, and likely play an important role in guiding who one is gravitated towards (or away). In a sea of potential partners, these subtle evaluative responses and inferences occurring outside of conscious awareness begin to shape the likelihood of learning more about the person - the very initial steps in the path towards an attachment bond.

2. Infatuation. Although not identified as a turning point in past work, from an attachment perspective, a pivotal event in the preattachment stage is the state of being infatuated with a potential partner (Günaydin et al. 2013; Tennov 1979). Infatuation manifests itself as constantly thinking about (Marazziti et al. 1999) and longing to be with the person (Aron et al. 2005). Such feelings are typically accompanied by physiological arousal and anxiety (Marazziti and Canale 2004). Infatuation focuses one's attention on one potential partner to the exclusion of all others (Tennov 1979) and thus might speed up one's progression to the next, attachmentin-the-making stage; a proposition needing further experimental investigation.

At the affective and neural level, infatuation in the preattachment stage has been linked to reward-related processing (e.g., Marazziti and Baroni 2012), which in turn may be associated with a heightened positive mental representation of the partner. Work has found that in early stage dating couples, photographs of the partner activate reward-related areas of the brain (Acevedo, this volume; Aron et al. 2005; Bartels and Zeki 2000). Although speculative and in need for empirical testing, animal research suggests the possibility that the heightened positivity may be coupled with inhibition of negative (e.g., Moriceau and Sullivan 2005). 
3. If ... Then ... Dyadic Patterns. The turning points in the preattachment phase offer individuals opportunities to get to know one another. As they do, mental representations are updated to reflect the new information acquired through mutual interactions although initial impressions still color representations (e.g., Fiske and Neuberg 1990; Funder 2012). Despite this, the partner has not yet been integrated into the self. Consequently, the CAPS networks of the two individuals are still relatively asynchronous, meaning that the two individuals are still getting to know one another and do not yet have stable patterns of behaving when they are together. Thus, the behavioral signature arising from their interactions is not yet stable, reflecting the fact that they have not yet formed an effective "coupled" dyadic cognitive system.

\section{Attachment-in-the-Making}

In the attachment-in-the-making stage, individuals preferentially seek proximity to one another and increasingly engage in behaviors (e.g., self-disclosures, physical contact, mutual gazing, kissing, sex) in which the other person, and the relationship, is the primary focal point of attention. Through these key turning points a number of changes occur at the level of the mental representation. These changes, in turn, promote the emergence of behaviors that collectively signify the making of an attachment bond, namely, proximity maintenance, safe haven, secure base, and separation distress.

1. Building a Robust, Context-Independent, Chronically Accessible Mental Representation of the Partner. Based on a review and synthesis of the extant literature, we believe that a prerequisite for the development of an attachment bond and its behavioral manifestations is the development of a robust, context-independent, and chronically accessible mental representation of the partner. That is, the mental representation of the potential partner must be built up and elaborated. In the preattachment phase, much of the partner representation is based on the perceiver's own past experiences. In the attachment-in-the-making stage, through a variety of mundane and significant interactions, this mental representation becomes updated with more information representing the partner. The development of a robust, contextindependent representation allows it to be easily activated in a number of situations and to guide behaviors.

One key turning point identified in previous work is simply spending a greater proportion of time together. Interestingly, previous work has found that the sheer quantity of exposure may be more important for relationship development than the quality of time spent together (Baxter and Bullis 1986). We hypothesize even in the absence of intimate encounters, exposure allows individuals to learn about the varied cues associated with the partner (e.g., partner's scent, facial and bodily structure and movement, nonverbal behaviors, moods, and behavioral patterns) and encounter them in varied ways (e.g., from different viewpoints, displaying different emotions, under different lighting, speaking with different volume of voice, 
wearing different clothing, in different settings). With repeated exposure of these visual, auditory, olfactory, and tactile cues, the representation of the partner becomes richer and critically, more context-independent (i.e., view-invariant, robust). One consequence is that it can easily be activated in different contexts.

With greater exposure, the representation of the partner is also activated more frequently. Given that the frequency of construct activation is linearly related to chronic accessibility, spending time together is the first step to making the representation chronically accessible - easily brought to mind in a variety of situations. The idea that greater exposure leads to a mental representation of the partner that is richer, context-independent, and chronically accessible has consequences for affective responding. For example, any cue that is even remotely associated with the partner (e.g., an unknown other who shares a hobby with the partner) would be sufficient to activate the partner representation from memory. Moreover, cues associated with the partner should be processed more fluently and should elicit feelings of familiarity, which have been shown to promote liking (e.g., Reis et al. 2011).

Although initial interactions with potential mates may be superfluous, as past research suggests, they tend to gradually increase in intimacy over time. Accordingly, another turning point identified in the literature, which is a byproduct of proximity maintenance, is getting to know a potential mate. In contrast to the learning that occurs through sheer exposure, this turning point involves higher quality and more intimate interactions in which two people learn about and disclose personal information to each other. Not only do couples report greater commitment following such turning points (e.g., Gonzaga et al. 2001), experimental work shows that selfdisclosure increases feelings of intimacy and liking and leads to a sense of mutual trust (Aron et al. 1997; Collins and Miller 1994). Moreover, such activities may lead the two individuals to engage in novel activities together or share humorous experiences, which in turn elicit feelings of reward and further promote intimacy and liking (Aron et al. 2000; Fraley and Aron 2004).

With increased time together and intimacy, both individuals would eventually come to learn about each other's behavioral signatures. Sam may learn that Terry is chronically late when it comes to meeting up with friends but punctual for workrelated events. At a more intimate level, it may become clear that when worried, Terry becomes argumentative, but that talking about the worries, has a calming effect. Eventually, they become "experts" about one another's behavioral patterns (if...then... pattern) and would even describe the other in these terms (Wright et al. 1988). One benefit is that they can automatically anticipate how their partner would respond to different situations.

2. Conditioning the affective, cognitive, and behavioral responses. A key characteristic of an attachment bond is that the two individuals' affective, cognitive, and behavioral responses become intricately attuned to one another (see Selcuk et al. 2010). In the attachment-in-the-making phase, a number of events transpire that not only involve each person learning relatively abstract information about their partner (e.g., hometown, favorite restaurant, biggest dream), but also involve conditioning each other's affective and physiological responses to the other partner's cues. 
A turning point identified in the literature that naturally reflects this preferential treatment of the partner, which may promote the conditioning of one another's responses, is exclusivity in which individuals typically break their involvement with other potential mates and start spending time exclusively with one another. The development of partner representation at this stage is generally influenced by two types of turning points: positive arousing episodes (e.g., sex) and comfort-seeking episodes to cope with negative experiences (e.g., day-to-day stressors). Both types of experiences typically have an arousal phase, which is followed by a calm quiescent state, which, if repeated over time, facilitates the formation of the attachment bond (see Beckes and Coan this volume for a discussion of distress-relief processes in promoting attachment security).

a. Positive Arousing Experiences. Positive arousing experiences that promote attachment formation include intimate self-disclosures, mutual gazing, physical contact, and sex. Simply being with the partner and engaging in these behaviors can elicit feelings of desire, high arousal, and anticipation of reward (e.g., Gonzaga et al. 2006), which have been linked with activation in dopamine-rich areas of the brain - such as the ventral tegmental area, nucleus accumbens, and caudate nucleus (Depue and Morrone-Strupinsky 2005). With repeated interactions with the partner, the partner representation comes to be automatically associated with these feelings of reward and positive affect (Zayas and Shoda 2005). Indeed, in fledgling relationships, activating the representation of one's romantic partner (vs. a close friend or a highly familiar acquaintance) was found to be associated with activity in rewardrelated areas of the brain - namely, the ventral tegmental area and caudate (Aron et al. 2005; Bartels and Zeki 2000; Xu et al. 2010).

Anticipation of reward characterized by high arousal and desire is thought to be followed by feelings of calm, comfort, and satisfaction if one's desire for intimacy is fulfilled (e.g., Carter 1998; Depue and Morrone-Strupinsky 2005). For example, activation of the HPA axis during sex is followed by oxytocin, vasopressin, and opioid release, which produces a calm state. When one repeatedly experiences feelings of comfort and satisfaction in the presence of the partner, mental representation of this person starts to be associated with these feelings, which in turn facilitates formation of the attachment bond (e.g., Depue and Morrone-Strupinsky 2005; Uvnäs-Moberg 1998). Of course, the attachment bond will be formed even when the partners do not engage in physically intimate behaviors or sex. It is possible however that these behaviors accelerate attachment formation although this possibility is yet to be empirically investigated.

b. Distress-Relief Experiences. In addition to positive arousing experiences, seeking comfort and support from the partner following stressful experiences is another turning point that has a profound influence on attachment formation (see Beckes and Coan, this volume). In times of stress, being comforted by a responsive partner leads to the release of oxytocin and opioids, which were shown to have anxietyreducing effects (e.g., Chong et al. 2006; Petrovic et al. 2008). For example, soft touch - which is a soothing behavior romantic partners typically engage in-leads 
to release of opioids, which produces a pleasant affective state (e.g., Löken et al. 2009).

After repeatedly encountering alleviation of negative affect in the presence of the partner, the mental representation of the partner starts to be associated with feelings of comfort and relief, strengthening the attachment bond. The idea that stress relief facilitates attachment formation is also supported by recent experimental work. For example, Beckes, Simpson, and Erikson showed that individuals developed more positive associations with smiling individuals preceded by a distressing stimulus (e.g., a snake) compared with those preceded by a neutral stimulus (e.g., a rolling pin). Von Dawans et al. (2012) found that participants who completed a stressful (vs. non-stressful) task in the lab subsequently tended to display behaviors indicative of trust and liking during economic games. This research suggests that seeking comfort from one's partner following a stressful experience helps associate the partner representation with feelings of relief and trust as well as strengthening the expectation that partner will be supportive and responsive in times of need (e.g., Baldwin et al. 1993).

3. If (situation)...Then (behavior)... Dyadic Patterns. Towards the end of the attachment-in-the-making stage, as the partner becomes more familiar, feelings of arousal and desire associated with the partner representation start to dampen while feelings of comfort, relief, and pleasantness continue to grow. As the two individuals get to know one another more intimately, their CAPS networks start to become interlocked and stable patterns of behaving with one another start to emerge. Yet, the behavioral signature arising from their interactions reflects the fact they have not formed a fully effective "coupled" cognitive system.

\section{Clear-Cut Attachment/Goal-Corrected Partnership}

At this stage, a full-fledged attachment bond is formed between the partners. We discuss clear-cut attachment and goal-corrected partnership stages together because as compared with infancy, it is harder to distinguish these two stages in adulthood, especially at the level of the representation. In infancy, the major distinction between the clear-cut attachment stage and the goal-corrected partnership stage is related to the cognitive development of the infant. In the clear-cut attachment stage, the infant reacts to temporary separations from the caregiver by showing overt signs of distress (e.g., crying) whereas in the goal-corrected partnership stage, the infant does not react as strongly to such separations (Hazan and Zeifman 1994). This is partly because the infant becomes cognitively capable of negotiating separations with the caregiver and is able to use the mental representation of the caregiver to derive comfort. Because adults are already capable of doing this in the clear-cut attachment stage, it is hard to make a clear distinction between this stage and goalcorrected partnership. Hence, we will discuss these two stages together in the current chapter. 
1. From Passion to Security. The partner representation acquires greater reward value as a clear-cut attachment bond is established. Indeed, individuals in established (vs. fledgling) relationships were found to show greater activation in ventral pallidum, a brain region implicated in reward processing (see Acevedo, this volume). However, as compared with the attachment-in-the-making stage, feelings of passion and high arousal experienced in the presence of the partner decline in the clear-cut attachment stage (e.g., Gonzaga et al. 2006; Sprecher and Regan 1998), along with sexual intimacy (Christopher and Sprecher 2000). Thus, activating the partner representation leads to less arousal but rather feelings of calm, comfort, and pleasantness. For example, activating one's spouse's representation (vs. a highly familiar acquaintance) elicits activation in areas of the brain rich in oxytocin and vasopressin receptors, which are known to induce a state of calm (Acevedo et al. 2012). Moreover, activation in these areas was found to be associated with self-reported friendship-based love, suggesting that feelings of calm and comfort derived from the partner representation is an important feature of clear-cut attachment.

Comfort-seeking is still an important turning point at the clear-cut attachment stage. However, one important difference from the attachment-in-the-making stage is that the partner representation now provides a safe haven even in the physical absence of the partner. For example, Selcuk et al. (2012) demonstrated the affect regulation benefits of activating the partner representation in couples who have been in a romantic relationship for at least a year, when previous work suggests a clear-cut attachment bond is likely to be formed (Zeifman and Hazan 2008). Specifically, viewing the partner's (vs. another participant's partner's) photograph helped participants recover from negative affect resulting from thinking about stressful memories. Importantly, the magnitude of this recovery effect predicted physical and mental health in-day-to-day life, demonstrating the critical role of attachment representations in affect regulation and well-being.

2. Synchronization of Affective, Physiological, and Behavioral Systems. The profound role a full-fledged attachment bond plays in affect regulation is also reflected in temporally coordinated affective and physiological responses of partners - a phenomenon called synchrony or co-regulation (see Sbarra and Hazan 2008). Synchrony is observed for daily affect (Butner et al. 2007) as well as for physiological responses including heart rate (Helmet al., in press) and cortisol response (Saxbe and Repetti 2010). Yet, the exact role mental representations play in development of synchrony is not known. It is possible that a detailed representation of the partner's affective and physiological responses is formed in clear-cut attachment and this representation facilitates synchrony effects. Then, synchrony should be observed even during unshared experiences in which partners cannot directly influence each other's affect and physiology. Butner et al. (2007) found that this was indeed the case. Specifically, synchrony in daily affect was observed even after statistically controlling for couples' shared experiences. Moreover, past work showed that even when probed separately, partners show similar affective responses to various events (e.g., successes, worries), with substantial convergence observed in couples who are together for over a year (Anderson et al. 2003). This suggests that the partner repre- 
sentation contains detailed knowledge about how the partner might feel, think, and act in different situations, which might be implicitly influencing one's physiology and affect even during unshared experiences. An interesting direction for future research is to investigate whether the synchrony effects depend on how detailed the partner representation is.

3. Separation Distress. Another turning point that brings about a host of important consequences is being involuntarily separated from the partner. One might be separated from the partner for a short duration - for example, because of a business trip - or for longer - for example, when the partners work in different cities. A psychological theme associated with separations is missing the partner, which is characterized by feeling sad, daydreaming about the partner, and talking to others about the partner (Le et al. 2008). Although individuals might cope with missing the partner by calling, texting, or emailing him/her, physical cues such as partner's warmth, scent, and touch — which are critical in regulating one's physiology and affect - are not available during separations. That is why, even separations that last only a few days have a host of negative consequences for one's well-being including disruption of sleep, poor appetite, and increased cortisol response (e.g., Diamond et al. 2008). It is possible that individuals who are better at using the partner representation to recover from negative affect (Selcuk et al. 2012) are less adversely affected from being separated from the partner although this possibility remains to be tested. Some positive feelings toward the partner (e.g., feelings of closeness, appreciation) also decline during separations, but so does criticism and conflict (Diamond et al. 2008). The relative absence of conflict might be one of the reasons why long-distance couples tend to be as satisfied in their relationships as geographically close couples (see Stafford 2010). Another reason might be that long-distance couples tend to have more idealized representations of one another (e.g., Jiang and Hancock 2013).

4. Commitment. Another important turning point marking clear-cut attachment is serious commitment. For example, participants who reported having discussed marriage with their partner expressed greater love and less sexual desire for their partner than those who reported not having discussed marriage (Gonzaga et al. 2006), suggesting that considering serious commitment is a turning point indicative of clearcut attachment. When two individuals seriously commit to the relationship-for example, get married - they typically experience feelings of reward and happiness (e.g., Clark et al. 2008), which infuses the partner representation with positivity. Whether positive effects of serious commitment on the partner representation are lasting depends on individual differences - for example, the extent to which partners idealize one another (Murray et al. 2011) or engage in constructive strategies to deal with conflict (Finkel et al. 2013).

5. If ... Then ... Dyadic Patterns. In addition to effects of the partner representation on information processing, the CAPS networks of the two individuals are interlocked at the clear-cut attachment stage - that is, stable patterns of behaving with one another are unequivocally observed. 


\section{Unanswered Questions and Future Directions}

This framework naturally sparks further questions about the process by which two individuals form an attachment bond in adulthood such as: what are the key turning points, do most people experience them, and if so, do they experience them in the same way, at the same time, and in the same order? We attempt to begin addressing a few of these questions below.

\section{Are All Turning Points Alike?}

The set of features present in particular turning points are likely to have different effects on how mental representations change. This is a logical assumption given that the process of changing mental representations involves the coactivation in short-term memory of the existing mental representation with the unique set of cues engendered by the particular turning point. It thus stands to reason that, if one turning point (first kiss) is associated with particular set of cues (touch, scent), and a different turning point (deciding to be exclusive or not) is associated with a different set of cues (psychological security and relationship stability), then the coupling of the mental representation with the first turning point will lead to different changes in long-term memory than the coupling of the mental representation with the second turning point.

\section{What About Individual Differences?}

The literature suggests that relational development is quite diverse (Huston et al. 1981). And this is perhaps the case now more than ever given the greater flexibility in people's lives. Thus, it is reasonable to assume that individual differences (e.g., adult attachment style) might play an important role in adult attachment formation and development.

Our argument is not that particular turning points will be the same for all individuals, occurring at the same time and experienced in a similar manner, but rather that these turning points are a time of learning and updating mental representations. It is during these key turning points where the mental representations undergo profound changes and the particular cues relevant to the turning points become linked with the representations. Moreover because turning points often involve tensions and themes, for example of self and other, these turning points have implications for representations of self and other.

We identified seemingly logical candidates for affecting attachment development of an average individual. Individual differences in these processes at all stages of attachment formation are inevitable. It is very likely that the turning points 
encountered are not random events, but that people have preferences towards or away from them (e.g., promiscuity, commitment). We are not arguing that there are no individual differences, but rather that these key events offer opportunities for changes in the mental representation. Future work should uncover how (or whether) the turning points discussed in this chapter and other work affect mental representations and identify whether different types of individuals (e.g., secure, anxious, avoidant) experience turning points differently.

Similarly, future research would need to empirically address whether the same objective event (e.g., first sexual encounter) occurring at a later stage of attachment formation has the same effect on the nature of the mental representation as if it had occurred in an earlier stage. From a social cognitive perspective, it is reasonable to hypothesize that the existing associations with a person's network, which would vary across stages of attachment formation, would affect how the event itself would be construed and, in turn, the effect of the event on the existing representations would be expected to vary. However, this is an empirical question.

\section{Are There Other Turning Points That Influence Attachment Development?}

The present chapter is not a comprehensive analysis of all of the turning points identified in previous research (e.g., Baxter and Bullis 1986) but rather a first attempt at identifying critical events that might influence development of an attachment bond based on extant literature on social cognition and relationship formation. Future work should empirically investigate whether turning points other than those described in this chapter might contribute to the development of attachment representations and how.

\section{How Does the Formation of a Romantic Attachment Differ From the Formation of a Platonic Attachment or Other Relationships?}

People readily learn information on subject matters that are personally meaningful and for which they already have existing information. So, not surprisingly, people are very efficient learners of social information in general. This process of interlocking is likely to occur for many different types of relationships. However, we expect that it will be most pronounced in a full-fledged attachment bond in which the interlocking occurs at various levels of functioning: behavioral, cognitive, affective, and physiological. What distinguishes more general social learning from attachment learning are the particular cues present during turning points (ventral ventral contact, repeated distress-relief interactions). However, future work might investigate similarities and differences in different types of bonds as a function of turning points experienced. 


\section{Concluding Thoughts}

In this chapter we have focused on understanding the normative processes by which two adults go from being mere acquaintances to forming a full-fledged adult attachment bond. We propose that turning points, whether they be a single event (the first kiss) or reoccurring events over a specified period of time (spending time together early on in the relationship), are fertile ground for significant changes in the mental representations that guide the behaviors of the two individuals. Initially, the two individuals" "minds," conceptualized as networks, are separate and disconnected from one another. However, at each turning point, the opportunity presents itself for greater integration of the partner in the self concept and for greater learning of the partner. Through processes of learning, the cues that individuals are exposed to during a particular turning point are associated with the mental representation of the partner, and over time with repeated exposure will become part of the enduring mental representation. Not only will the mental representation of the partner be enhanced, elaborated on, and made more chronically accessible, but mental representations of self and partner will become increasingly interconnected. Such integration should contribute to meaningful changes in the behavioral signature of the couple.

\section{References}

Acevedo, B. P., Aron, A., Fisher, H. E., \& Brown, L. L. (2012). Neural correlates of long-term intense romantic love. Social Cognitive and Affective Neuroscience, 7, 145-159.

Aharon, I., Etcoff, N., Ariely, D., Chabris, C. F., O’Connor, E., \& Breiter, H. C. (2001). Beautiful faces have variable reward value: fMRI and behavioral evidence. Neuron, 32, 537-551.

Andersen, S. M., \& Baum, A. (1994). Transference in interpersonal relations: Inferences and affect based on significant-other representations. Journal of Personality, 62, 459-497.

Andersen, S. M., \& Chen, S. (2002). The relational self: An interpersonal social-cognitive theory. Psychological Review, 109, 619-645.

Anderson, C., Keltner, D., \& John, O. P. (2003). Emotional convergence between people over time. Journal of Personality and Social Psychology, 84, 1054-1068.

Aron, A., Aron, E. N., \& Smollan, D. (1992). Inclusion of other in the self scale and the structure of interpersonal closeness. Journal of Personality and Social Psychology, 63, 596-612.

Aron, A., Melinat, E., Aron, E. N., Vallone, R. D., \& Bator, R. J. (1997). The experimental generation of interpersonal closeness: A procedure and some preliminary findings. Personality and Social Psychology Bulletin, 23, 363-377.

Aron, A., Norman, C. C., Aron, E. N., McKenna, C., \& Heyman, R. E. (2000). Couples' shared participation in novel and arousing activities and experienced relationship quality. Journal of Personality and Social Psychology, 78, 273-284.

Aron, A., Fisher, H., Mashek, D., Strong, G., Li, H., \& Brown, L. (2005). Reward, motivation and emotion systems associated with early-stage intense romantic love. Journal of Neurophysiology, 93, 327-337.

Atkinson, R. C., \& Shiffrin, R. M. (1968). Human memory: A proposed system and its control processes. In K. W. Spence \& J. T. Spence (Eds.), The psychology of learning and motivation: Advances in research and theory (Vol. II, pp. 89-195). New York: Academic. 
Baldwin, M. W., Fehr, B., Keedian, E., Seidel, M., \& Thomson, D. W. (1993). An exploration of the relational schemas underlying attachment styles: Self-report and lexical decision approaches. Personality and Social Psychology Bulletin, 19, 746-754.

Baldwin, M. W., Keelan, J. P. R., Fehr, B., Enns, V., \& Koh-Rangarajoo, E. (1996). Social-cognitive conceptualization of attachment working models: Availability and accessibility effects. Journal of Personality and Social Psychology, 71, 94-109.

Bartels, A., \& Zeki, S. (2000). The neural basis of romantic love. Neuroreport, 11, 3829-3834.

Baxter, L. A., \& Bullis, C. (1986). Turning points in developing romantic relationships. Human Communication Research, 12, 469-493.

Baxter, L. A., \& Erbert, L. A. (1999). Perceptions of dialectical contradictions in turning points of development in heterosexual romantic relationships. Journal of Social and Personal Relationships, 16, 547-569.

Beckes, L., Simpson, J. A., \& Erickson, A. (2010). Of snakes and succor: Learning secure attachment associations with novel faces via negative stimulus pairings. Psychological Science, 21, 721-728.

Bolton, C. D. (1961). Mate selection as the development of a relationship. Marriage and Family Living, 23, 234-240.

Bowlby, J. (1982). Attachment and loss: Vol. 1. Attachment (2nd ed.). New York: Basic Books.

Bruner, J. S. (1957). On perceptual readiness. Psychological Review, 64, 123-152.

Butner, J., Diamond, L. M., \& Hicks, A. M. (2007). Attachment style and two forms of affect coregulation between romantic partners. Personal Relationships, 14, 431-455.

Cairns, R. B. (1966). Attachment behavior of mammals. Psychological Review, 73, 409-426.

Carter, C. S. (1998). Neuroendocrine perspectives on social attachment and love. Psychoneuroendocrinology, 23, 779-818.

Chong, R. Y., Oswald, L., Yang, X., Uhart, M., Lin, P. I., \& Wand, G. S. (2006). The Micro-opioid receptor polymorphism A118G predicts cortisol responses to naloxone and stress. Neuropsychopharmacology, 31, 204-211.

Christensen, A., \& Nies, D. C. (1980). The spouse observation checklist: Empirical analysis and critique. American Journal of Family Therapy, 8, 69-79.

Christopher, F. S., \& Sprecher, S. (2000). Sexuality in marriage, dating, and other relationships: A decade review. Journal of Marriage and Family, 62, 999-1017.

Clark, A. E., Diener, E., Georgellis, Y., \& Lucas, R. E. (2008). Lags and leads in life satisfaction: A test of the baseline hypothesis. The Economic Journal, 118, F222-243.

Collins, N. L., \& Miller, L. C. (1994). Self-disclosure and liking: A meta-analytic review. Psychological Bulletin, 116, 457-475.

von Dawans, B., Fischbacher, U., Kirschbaum, C., Fehr, E., \& Heinrichs, M. (2012). The social dimension of stress reactivity acute stress increases prosocial behavior in humans. Psychological Science, 23, 651-660.

Depue, R. A., \& Morrone-Strupinsky, J. V. (2005). A neurobiobehavioral model of affiliative bonding: Implications for conceptualizing a human trait of affiliation. Behavioral and Brain Sciences, 28, 313-395.

Diamond, L. M., Hicks, A. M., \& Otter-Henderson, K. D. (2008). Everytime you go away: Changes in affect, behavior, and physiology associated with travel-related separations from romantic partners. Journal of Personality and Social Psychology, 95, 385-403.

Finkel, E. J., Slotter, E. B., Luchies, L. B., Walton, G. M., \& Gross, J. J. (2013). A brief intervention to promote conflict reappraisal preserves marital quality over time. Psychological Science, 24, 1595-1601.

Fiske, S. T., \& Neuberg, S. L. (1990). A continuum of impression formation, from category based to individuating processes: Influences of information and motivation on attention and interpretation. In M. P. Zanna (Ed.), Advances in experimental social psychology (Vol. 23, pp. 1-74). San Diego: Academic.

Fraley, B., \& Aron, A. (2004). The effect of a shared humorous experience on closeness in initial encounters. Personal Relationships, 11, 61-78. 
Funder, D. C. (2012). Accurate personality judgment. Current Directions in Psychological Science, 21, 177-182.

Gonzaga, G. C., Keltner, D., Londahl, E. A., \& Smith, M. D. (2001). Love and the commitment problem in romantic relations and friendship. Journal of Personality and Social Psychology, $81,247-262$.

Gonzaga, G. C., Turner, R. A., Keltner, D., Campos, B., \& Altemus, M. (2006). Romantic love and sexual desire in close relationships. Emotion, 6, 163-179.

Goodwin, S. A., Fiske, S. T., Rosen, L. D., \& Rosenthal, A. M. (2002). The eye of the beholder: Romantic goals and impression biases. Journal of Experimental Social Psychology, 38, 232-241.

Günaydin, G., Zayas, V., Selcuk, E., \& Hazan, C. (2012). I like you but I don't know why: Objective facial resemblance to significant others influences snap judgments. Journal of Experimental Social Psychology, 48, 350-353.

Günaydin, G., Selcuk, E., \& Hazan, C. (2013). Finding the one: A process model of human mate selection. In C. Hazan \& M. Campa (Eds.), Human bonding (pp. 103-131). New York: Guilford.

Hazan, C., \& Zeifman, D. (1994). Sex and the psychological tether. In K. Bartholomew \& D. Perlman (Eds.), Advances in personal relationships: Attachment processes in adulthood (Vol. 5, pp. 151-177). London: Jessica Kingsley.

Hazan, C., Gur-Yaish, N., \& Campa, M. (2004). What does it mean to be attached? In W. S. Rholes \& J. A. Simpson (Eds.), Adult attachment: New directions and emerging issues (pp. 55-85). New York: Guilford.

Hebb, D. O. (1969). The organization of behavior. Wiley: New York.

Helm, J. L., Sbarra, D., \& Ferrer, E. (2012). Assessing cross-partner associations in physiological responses via coupled oscillator models. Emotion, 12, 748-762.

Higgins, E. T., \& King, G. (1981). Accessibility of social constructs: Information processing consequences of individual and contextual variability. In N. Cantor \& J. F. Kihlstrom (Eds.), Personality, cognition, and social interaction (pp. 69-121). Hillsdale: Erlbaum.

Hofer, M. A. (1994).Hidden regulators in attachment, separation, and loss. Monographs of the Society for Research in Child Development, 59, 250-283.

Hönekopp, J. (2006). Once more: Is beauty in the eye of the beholder? Relative contributions of private and shared taste to judgments of facial attractiveness. Journal of Experimental Psychology: Human Perception and Performance, 32, 199-209.

Huston, T. L., Surra, C. A., Fitzgerald, N. M., \& Cate, R. M. (1981). From courtship to marriage: Mate selection as an interpersonal process. Personal Relationships, 2, 53-88.

Jacobson, N. S., \& Moore, D. (1981). Spouses as observers of the events in their relationship. Journal of Consulting and Clinical Psychology, 49, 269-277.

Jiang, L. C., \& Hancock, J. T. (2013). Absence makes the communication grow fonder: Geographic separation, interpersonal media, and intimacy in dating relationships. Journal of Communication, 63, 556-577.

Kampe, K. K., Frith, C. D., Dolan, R. J., \& Frith, U. (2001). Reward value of attractiveness and gaze. Nature, 413, 589-589.

Kim, H., Adolphs, R., O’Doherty, J. P., \& Shimojo, S. (2007). Temporal isolation of neural processes underlying face preference decisions. Proceedings of the National Academy of Sciences, 104, 18253-18258.

Kraus, M. W., \& Chen, S. (2010). Facial-feature resemblance elicits the transference effect. Psychological Science, 21, 518-522.

Le, B., Loving, T. J., Lewandowski, G. W., Feinberg, E. G., Johnson, K. C., Fiorentino, R., \& Ing, J. (2008). Missing a romantic partner: A prototype analysis. Personal Relationships, 15 , $511-532$.

Löken, L. S., Wessberg, J., McGlone, F., \& Olausson, H. (2009). Coding of pleasant touch by unmyelinated afferents in humans. Nature Neuroscience, 12, 547-548.

Macrae, C. N., \& Quadflieg, S. (2010). Perceiving people. In S. T. Fiske, D. T. Gilbert, \& G. Lindzey (Eds.), Handbook of social psychology (Vol. 1, 5th ed., pp. 428-463). New York: Wiley. 
Marazziti, D., \& Baroni, S. (2012). Romantic love: The mystery of its biological roots. Clinical Neuropsychiatry, 9, 14-19.

Marazziti, D., \& Canale, D. (2004). Hormonal changes when falling in love. Psychoneuroendocrinology, 29, 931-936.

Marazziti, A., Akiskal, H. S., Rossi, A., \& Cassano, G. B. (1999). Alteration of the platelet serotonin transporter in romantic love. Psychological Medicine, 29, 741-745.

Mikulincer, M., Gillath, O., \& Shaver, P. R. (2002). Activation of the attachment system in adulthood: threat-related primes increase the accessibility of mental representations of attachment figures. Journal of Personality and Social Psychology, 83, 881-895.

Mischel, W., \& Shoda, Y. (1995). A cognitive-affective system theory of personality: Reconceptualizing situations, dispositions, dynamics, and invariance in personality structure. Psychological Review, 102, 246-268.

Moriceau, S., \& Sullivan, R. M. (2005). Neurobiology of infant attachment. Developmental Psychobiology, 47, 230-242.

Murray, S. L., Griffin, D. W., Derrick, J. L., Harris, B., Aloni, M., \& Leder, S. (2011). Tempting fate or inviting happiness? Unrealistic idealization prevents the decline of marital satisfaction. Psychological Science, 22, 619-626.

Petrovic, P., Kalisch, R., Singer, T., \& Dolan, R. J. (2008). Oxytocin attenuates affective evaluations of conditioned faces and amygdale activity. Journal of Neuroscience, 28, 6607-6615.

Reis, H. T., Maniaci, M. R., Caprariello, P. A., Eastwick, P. W., \& Finkel, E. J. (2011). Familiarity does indeed promote attraction in live interaction. Journal of Personality and Social Psychology, 101, 557-570.

Saxbe, D. E., \& Repetti, R. L. (2010). For better or worse? Coregulation of couples' cortisol levels and mood states. Journal of Personality and Social Psychology, 98, 92-103.

Sbarra, D. A., \& Hazan, C. (2008). Coregulation, dysregulation, self-regulation: An integrative analysis and empirical agenda for understanding adult attachment, separation, loss, and recovery. Personality and Social Psychology Review, 12, 141-167.

Selcuk, E., Zayas, V., \& Hazan, C. (2010). Beyond satisfaction: The role of attachment in marital functioning. Journal of Family Theory and Review, 2, 258-279.

Selcuk, E., Zayas, V., Günaydin, G., Hazan, C., \& Kross, E. (2012). Mental representations of attachment figures facilitate recovery following upsetting autobiographical memory recall. Journal of Personality and Social Psychology, 103, 362-378.

Shoda, Y., \& Mischel, W. (1998). Personality as a stable cognitive-affective activation network: Characteristic patterns of behavior variation emerge from a stable personality structure. In S. J. Read \& L. C. Miller (Eds.), Connectionist models of social reasoning and social behavior (pp. 175-208). NJ: Lawrence Erlbaum.

Sillars, A., \& Scott, M. (1983). Interpersonal perception between intimates: An integrative review. Human Communication Research, 10, 153-176.

Sprecher, S., \& Regan, P. C. (1998). Passionate and companionate love in courting and young married couples. Sociological Inquiry, 68, 163-185.

Stafford, L. (2010). Geographic distance and communication during courtship. Communication Research, 37, 275-297.

Tennov, D. (1979). Love and limerence: The experience of being in love. New York: Stein and Day.

Tulving, E. (1972). Episodic and semantic memory. In E. Tulving \& W. Donaldson (Eds.), Organization of memory (pp. 382-403). New York: Academic.

Uvnäs-Moberg, K. (1998). Oxytocin may mediate the benefits of positive social interaction and emotions. Psychoneuroendocrinology, 23, 819-835.

White, G. L., \& Shapiro, D. (1987). Don't I know you? Antecedents and social consequences of perceived familiarity. Journal of Experimental Social Psychology, 23, 75-92.

Xu, X., Aron, A., Brown, L., Cao, G., Feng, T., \& Weng, X. (2010). Reward and motivation systems: A brain mapping study of early-stage intense romantic love in Chinese participants. $\mathrm{Hu}$ man Brain Mapping, 32, 249-257. 
Zayas, V., \& Shoda, Y. (2005). Do automatic reactions elicited by thoughts of romantic partner, mother, and self relate to adult romantic attachment? Personality and Social Psychology Bulletin, 31, 1011-1025.

Zayas, V., Shoda, Y., \& Ayduk, O. N. (2002). Personality in context: An interpersonal systems perspective. Journal of Personality, 70, 851-898.

Zayas, V., Whitsett, D., Lee, J. J. Y., Wilson, N., \& Shoda, Y. (2008). From situation assessment to personality: Building a social-cognitive model of a person. In G. Boyle, G. Matthews, \& D. Saklofske (Eds.), Handbook of personality theory and testing (Vol. 2, pp. 377-401). Thousand Oaks CA: Sage.

Zeifman, D., \& Hazan, C. (1997). Attachment: The bond in pair-bonds. In J. A. Simpson \& D. T. Kenrick (Eds.), Evolutionary social psychology (pp. 237-263). Mahwah: Erlbaum.

Zeifman, D., \& Hazan, C. (2008). Pair bonds as attachments: Reevaluating the evidence. In J. Cassidy \& P. R. Shaver (Eds.), Handbook of attachment: Theory, research, and clinical applications (2nd ed., pp. 436-455). New York: Guilford. 